\title{
LM-2
}

\section{FATTY ACID COMPOSITION AND VOLATILE COMPOUNDS OF CAVIAR FROM FARMED WHITE STURGEON (ACIPENSER TRANSMONTANUS)}

\author{
Fabio Caprino ${ }^{1}$, Federica Bellagamba ${ }^{2^{*}}$, Maria Letizia Busetto ${ }^{3}$, Ivan Giani ${ }^{4}$, \\ Mario Pazzaglia ${ }^{5}$, Vittorio Maria Moretti ${ }^{6}$ \\ 12346 Department of Science and Technology for Food Safety, University of Milan, Italy \\ ${ }^{5}$ Agroittica Lombarda, Calvisano (BS), Italy \\ * Corresponding author - E-mail: federica.bellagamba@unimi.it; Phone: 003902 50315759;
}

Caviars are the salt-cured and preserved eggs of many sturgeon species that have been separated from the supporting connective tissue. The most famous and valuable caviars are produced from harvested sturgeons in the area of Caspian Sea, namely Beluga (Huso huso), Osetra (Acipenser gueldenstaedtii) and Sevruga caviar (Acipenser stellatus). Over the past few decades, owing to the strong demand for sturgeon caviar, the over-exploitation of natural stocks has led to a dramatic decreases of the supplies. To protect these endangered species, in 1997 the Convention on International Trade in Endangered Species of Wild Fauna and Flora (CITES) decided to limit trade of caviar by listing all sturgeon species on the Annex II of the convention.

The lack of supply and the continuous demand for this product have increased the feasibility of caviar production from aquaculture. There are high quality and environmentally friendly alternatives available such as caviar produced from farmed white sturgeon (Acipenser transmontanus) in Italy, Siberian sturgeon (Acipenser baerii) in France and Germany, Adriatic sturgeon (Acipenser naccarii) in Italy and Spain. Among pure species, Acipenser stellatus, the beluga and the paddlefish (Polyodon spathula) are reared mainly in extensive or semi-intensive farming on a limited scale. The successful of producing caviar from farmed sturgeon has arisen several investigations aiming to produce the chemical characterization of the product. Biochemical assays together with sensory studies have been carried out with the purpose to determine whether compositional and sensory differences might be observed between caviar from farmed and wild sturgeon.

The study was designed to characterize caviar from farmed white sturgeons (Acipenser transmontanus) subjected to different dietary treatments before eggs collection. Fifty caviar samples from fifty farmed sturgeons have been analyzed for proximate composition, fatty acid and volatile compounds. 